\title{
CORRECTION
}

\section{Correction to: Wound care quality of life in aging patients undergoing electrodessication and curettage on the back}

\author{
Kara Pretzlaff ${ }^{1} \cdot$ Lindsey West $^{1} \cdot$ Michael N. Nemeh $^{1} \cdot$ Divya Srivastava $^{1} \cdot$ Rajiv I. Nijhawan $^{1}$ (D)
}

Published online: 22 October 2021

(c) The Author(s), under exclusive licence to Springer-Verlag GmbH Germany, part of Springer Nature 2021

Correction to: Archives of Dermatological Research https://doi.org/10.1007/s00403-021-02248-5

In this article the caption to Fig. 1 was incorrect; the Fig. 1

caption should have appeared as shown below.

The original article can be found online at https://doi.org/10.1007/ s00403-021-02248-5.

Rajiv I. Nijhawan

rajiv.nijhawan@utsw.edu

1 Department of Dermatology, University of Texas

Southwestern Medical Center, 5939 Harry Hines Blvd, 4th

Floor, Suite 100, Dallas 75390-9191, USA 
Fig. 1 Wound quality of life survey given to our patients. Of note, the Wound-QoL instrument displayed in this figure was slightly modified for the purposes of this study. The original wording of the Wound-QoL instructions reads as follows: "Wound-QoL questionnaire on quality of life with chronic wounds. With the following questions, we aim to find out how your chronic wound(s) affect(s) your quality of life. Please tick one box per line!"
Wound-QOL Survey

Please answer the following questions to the best of your ability. These questions are trying to assess how wound care has affected your quality of life in the last seven days.

In the last seven days:

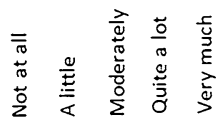

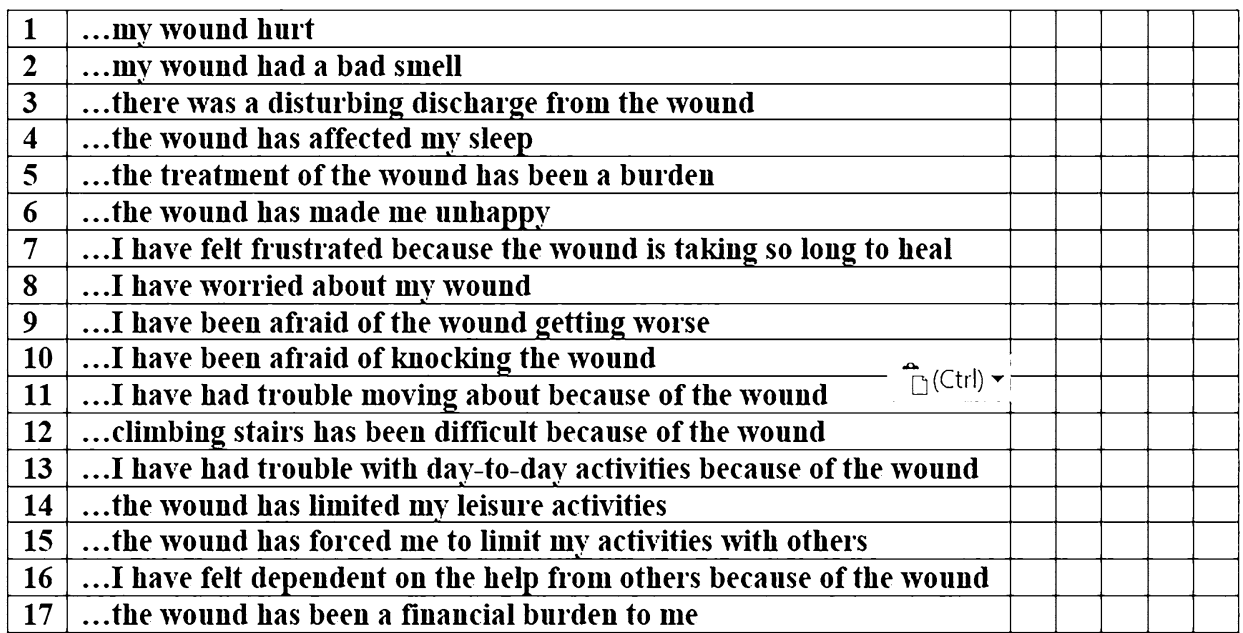

Publisher's Note Springer Nature remains neutral with regard to jurisdictional claims in published maps and institutional affiliations. 